\title{
A INFLUÊNCIA DA MEMÓRIA NA FORMAÇÃO DOS ESPAÇOS URBANOS NA AMAZÔNIA SETENTRIONAL
}

\author{
Max André Araújo Ferreira ${ }^{1}$ \\ Roberto Rigaud Navega Costa ${ }^{2}$
}

\begin{abstract}
RESUMO: O intuito deste artigo é o de pensar como a memória influencia na formação dos espaços urbanos e como ela vem sendo estudada em diversas áreas do conhecimento. $\mathrm{O}$ interesse no tema da formação dos espaços urbanos parte da premissa de que esses espaços se formam no sentido de preservar a memória de determinado povo. Em Boa Vista, capital do Estado de Roraima, existem seis feiras livres regulamentadas pela prefeitura municipal, algumas delas são tradicionais, onde são preservadas a memória e o objetivo para o qual foram criadas. Outras foram criadas para atender a uma demanda específica, mas ao longo de sua existência novas dinâmicas fizeram com que seus usuários esquecessem essa memória. O Centro Comercial Caxambú também é um local onde são preservadas as memórias coletivas, começando pelo nome, sendo uma homenagem ao primeiro camelô de Roraima. Foram convidados para o diálogo autores como Maurice Halbwachs, Michael Pollak, entre outros. O artigo em tela faz um breve levantamento de como a memória vem sendo abordada por esses autores, partindo do conceito de memória individual, caminhando à memória coletiva ou social, tendo como fim a influência da memória na formação de determinados espaços urbanos.
\end{abstract}

Palavras-chave: Memória Social; Espaços Urbanos; Feiras Livres.

\section{THE INFLUENCE OF MEMORY IN THE FORMATION OF URBAN SPACES IN THE NORTH AMAZON}

\footnotetext{
${ }^{1}$ Doutorado em andamento em Sociedade, Cultura e Fronteiras pela Universidade Estadual do Oeste do Paraná, Mestre em Sociedade e Fronteiras pela Universidade Federal de Roraima, Especialista em Contabilidade Pública e Responsabilidade Fiscal pela Faculdade Internacional de Curitiba, Graduado em Ciências Contábeis pela Universidade Federal de Roraima, atualmente exerce o cargo de Professor Adjunto da Universidade Federal de Roraima, sendo lotado no Departamento de Contabilidade onde exerce suas funções como Professor. Foi Chefe Pró Tempore do Departamento de Contabilidade da Universidade Federal de Roraima entre dezembro de 2017 a abril de 2019. É membro dos Conselhos Editoriais da Revista da Administração de Roraima e Revista Gestão e Análise. Pesquisador do Núcleo de Estudos em Administração e Negócios. Pesquisador do Núcleo Amazônico de Pesquisa em Relações Internacionais. Pesquisador do Grupo de Estudos e Pesquisas Avançadas em Administração, Inovação e Tecnologias da Informação e Comunicação, Estudante do Grupo de Pesquisa Interdisciplinaridade, Comunicação \& Políticas Públicas e Estudante do Grupo de Estudo Interdisciplinar sobre Fronteiras: Processos Sociais e Simbólicos (GEIFRON/UFRR). E-mail: max.andre@ufrr.br

${ }^{2}$ Possui graduação em Filosofia pela Universidade do Sul de Santa Catarina (2018). Tem experiência na área de Filosofia, com ênfase em Epistemologia. Foi selecionado para a vaga de Aluno Especial de Mestrado no Programa de Pós-Graduação em Sociedade, Cultura e Fronteiras da Unioeste - Foz do Iguaçu, para o curso Teoria do Estado no Pensamento Marxista, ministrado pela Prof ${ }^{a}$ Dr $^{\text {a }}$ Silvana Aparecida de Souza. Ingressou como mestrando no Pós-Graduação em Sociedade, Cultura e Fronteiras da Unioeste - Foz do Iguaçu, em 2019, com o projeto Combate ao Descaminho em Foz do Iguaçu, sob orientação do Prof Dr Eric G Cardin. E-mail: ramosnavega@gmail.com
} 
ABSTRACT: The purpose of this article is to think about how memory influences the formation of urban spaces and how it has been studied in several areas of knowledge. The interest in the theme of the formation of urban spaces starts from the premise that these spaces are formed in order to preserve the memory of a specific people. In Boa Vista, capital of the State of Roraima, there are six free fairs regulated by the city hall, some of which are traditional, where the memory and the purpose for which they were created are preserved. Others were created to meet a specific demand, but throughout its existence new dynamics have made its users forget this memory. The Caxambú Shopping Center is also a place where collective memories are preserved, starting with the name, paying homage to the first street vendor in Roraima. Authors such as Maurice Halbwachs, Michael Pollak, among others, were invited to the dialogue. The article on screen makes a brief survey of how memory has been approached by these authors, starting from the concept of individual memory, moving towards collective or social memory, aiming at the influence of memory in the formation of certain urban spaces.

Keywords: Social Memory; Urban spaces; Free fairs.

\section{INTRODUÇÃO}

O presente artigo discute o espaço de memória nas feiras livres da cidade de Boa Vista/RR. Tais espaços são utilizados pela população na busca por produtos mais baratos, sendo muitos desses, oriundos da Guiana e Venezuela. Localizadas em diferentes bairros da cidade essas feiras são conhecidas por ofertarem diversos tipos de produtos nacionais e importados.

O espaço geográfico discutido neste artigo está localizado na capital mais setentrional do Brasil, a cidade de Boa Vista, capital do Estado de Roraima. Boa Vista é a única capital brasileira acima da linha do Equador, possui uma população segundo o IBGE (2010) de 284.313 mil pessoas. Seu surgimento inicia-se com a sede de uma fazenda chamada de Boa Vista do Rio Branco no século XIX.

Conforme aponta Vale (2007, p.22), até o início da década de 1980, a expansão urbana da capital roraimense foi dirigida pelo governo federal que, "visando a segurança nacional, promoveu o crescimento populacional do Território por meio de uma política urbana concentrada na capital [...]”. Com isso foram surgindo diferentes microcentros em diferentes pontos da cidade.

Com a evolução das cidades, ao longo dos anos, os centros comerciais foram migrando para as periferias para atender à necessidade dos consumidores que formavam bairros mais afastados, foram criados pelo poder público pequenos centros comerciais, 
nesses locais foram se desenvolvendo como microcentros ${ }^{3}$, os quais se tornaram um importante aliado para o crescimento econômico da cidade de Boa Vista.

As feiras livres rotativas de Boa Vista foram regulamentadas pela lei $\mathrm{n}^{\circ} 402$, de 12 de novembro de 1996. Em Boa Vista funcionam as Feiras do Produtor, no bairro São Vicente, Feira do Passarão, no bairro Asa Branca, Feira do São Francisco, no Centro, Feira do São Vicente, no bairro de mesmo nome, Feira do Garimpeiro entre os bairros de Caimbé e Tancredo Neves e a Feira do Pintolândia, no bairro Pintolândia.

Para essa pesquisa foram selecionadas as três principais feiras livres da capital de Roraima por serem mais movimentadas, são elas a Feira do São Francisco, Feira do Garimpeiro e Feira do Produtor. Outro local escolhido foi o Centro Comercial Caxambú, conhecido por concentrar vendedores ambulantes organizados em uma estrutura cedida pela Prefeitura de Boa Vista. O local obedece a mesma dinâmica de outras capitais no Brasil.

Com isso, o problema da pesquisa compreende-se em saber-se como se deu a construção da memória social nas feiras livres na cidade de Boa Vista, Roraima. A metodologia utilizada parte de uma análise realizada por meio de uma revisão da literatura, sendo caracterizada quanto aos fins, ao meio e aos métodos, respectivamente em histórico, teórico e dedutivo, com revisões bibliográficas realizadas em livros e portais eletrônicos.

A primeira parte do texto inicia com alguns conceitos desenvolvidos por autores como Pensavento e Halbwachs, esse último é o responsável por desenvolver o conceito de memória coletiva ou social. Superada essa fase, a pesquisa evolui para o diálogo com os autores críticos às teorias de Halbwachs. É o caso, por exemplo, de Bloch, Blondel e Pollak.

Na segunda parte da pesquisa é discutido a formação dos espaços urbanos, esse diálogo então é construído com o apoio de Pensavento, a autora é referência para diversas outras pesquisas nessa mesma perspectiva. Finalizando o artigo, são inseridas nesse contexto as feiras livres e o centro comercial na cidade de Boa Vista/RR, sendo

\footnotetext{
${ }^{3}$ Para Licea (2012) microcentros são espaços caracterizados localizados em áreas centrais da cidade, onde já existe a infra-estrutura de transportes necessária, como redes de metrô, estradas, serviços de água, esgoto, energia elétrica, além de integrado no projeto de instalações e fachadas.
} 
esses exemplos de locais que receberam influências das memórias sociais em sua formação.

\section{A FORMAÇÃO DO CONCEITO DE MEMÓRIA COLETIVA}

Construir memórias é uma tarefa exclusivamente humana, para tal feito o homem precisa interagir com coisas ou pessoas no seu dia a dia para que essas sejam ativadas. Segundo Pensavento (2005) a memória é, por definição, uma luta contra o esquecimento. E essa luta se faz presente na vida das pessoas, nas ruas, nos prédios históricos, bem como na academia, sendo discutido em vários campos do conhecimento.

Mas como a memória se organiza? Sobre a organização da memória Filoux (1966) lembra que essa obedece a algumas características próprias, como de unir o atual e o inatual para depois realizar um modo 'intemporal' de consciência, uma experiência 'em contratempo'. Nessa definição o autor parece esclarecer como a memória se organiza para o ser humano.

Os primeiros estudos tentando pensar memória e a sua relação com a sociedade aparecem a partir dos estudos de Maurice Halbwachs. O autor desenvolve o conceito de memória coletiva inaugurando o campo de estudos sobre a memória na área das ciências sociais. Até o início do século XX, “a memória era o objeto de reflexão por excelência dos filósofos, que nela procuravam o acesso à compreensão do significado da vida humana" (SANTOS, 2012, p. 16).

Dentro da perspectiva sociológica, Halbwachs estabeleceu o conceito de memória coletiva, sendo essa influenciada pelos quadros sociais que a antecedem e a determinam. O autor é seguidor de Émile Durkheim, e sua contribuição é construir uma nova ideia para o termo memória, elevando com isso o patamar das discussões entre memória individual e memória social.

Halbwachs (2006) afirma que a memória é um processo de reconstrução, não se tratando de uma repetição linear dos acontecimentos e vivências no contexto de interesses atuais, ou seja, se diferencia dos acontecimentos e vivências que podem ser evocados e localizados em um determinado tempo e espaço, envoltos num conjunto de relações sociais. 
Ao relatar o processo de reconstrução da memória, o autor afirma que não se trata de uma repetição linear dos acontecimentos e vivências no contexto de interesses atuais. Desse modo ela se diferencia dos acontecimentos e vivências do indivíduo, podendo ser ativada em um determinado tempo e espaço, submersa em determinados conjuntos de relações sociais.

Halbwachs (2006) defende seu argumento dizendo que a lembrança se dá através de uma comunidade afetiva, com indivíduos se relacionando entre si ou em um grupo social. Desse modo, a lembrança individual se baseia na lembrança dos grupos nos quais esse indivíduo está inserido, recebendo então a influência destes.

Tal pensamento afirma que a memória individual é o resultado da combinação das memórias de diferentes grupos dos quais esse indivíduo está inserido, ou seja, sofre influência desses grupos, como, por exemplo, a família, os amigos, a igreja entre outros. Partindo desse ponto de vista é correto afirmar que esse indivíduo participa tanto da memória individual quanto da memória social.

Algumas afirmações quanto ao uso da memória são duramente criticadas, uma vez que essas não possuem a capacidade de armazenar todo o conhecimento vivido, a memória então passa por um processo de esquecimento, uma seleção de informações, onde essas são selecionadas através das lembranças mais importantes para aquele indivíduo.

O trabalho de Maurice Halbwachs intitulado "A memória social”, de 1968, é um dos responsáveis para que o termo comece a ganhar notoriedade acadêmica, se afastando totalmente dos conceitos já implementados pela história, biologia, psicologia, entre outros.

Dessa forma, Halbwachs argumenta que o pensamento coletivo comanda a sociedade através de uma "lógica da percepção que se impõe ao grupo e que o ajuda a compreender e a combinar todas as noções que lhe chegam do mundo exterior" (HALBWACHS, 2006, p. 61). O autor entende que o ser humano é capaz de atribuir ideias, reflexões, sentimentos e emoções do grupo que faz parte, sendo inspirado por ele.

As ideias aqui defendidas pelo autor vão a favor do pensamento de Durkheim, nesse ponto Pensavento destaca que: 


\begin{abstract}
como assinala Durkheim, há um ponto em que a memória social, fruto em parte de uma vida em comum, das tradições e de uma certa noção de herança recebida, se transforma em memória coletiva, que corresponde ao modo como, institucional e culturalmente, uma comunidade passa a evocar, construir e transmitir seu passado (PENSAVENTO, 2005, p. 13).
\end{abstract}

Neste sentido Halbwachs (2006, p. 65) afirma que "são os indivíduos que se lembram, enquanto integrantes do grupo (...) cada memória individual é um ponto de vista sobre a memória social”, sendo essa modificada conforme o lugar que o indivíduo ocupa no grupo. O autor, então, entende a importância de determinadas pessoas para o grupo que está inserido, sendo ativadas, portanto, as lembranças na formação da memória social.

Finalmente, Halbwachs (2006, p.102) conceitua a memória social como sendo "uma corrente de pensamento contínuo, de uma continuidade que nada tem de artificial, pois não retém do passado senão o que está vivo ou é capaz de viver na consciência do grupo que a mantém". Com isso, o autor afirma que a memória é fruto de testemunhos de uma determinada época, sendo remontada quando ativada.

É importante deixar claro que esses conceitos são criticados por alguns autores. Algumas dessas críticas dizem respeito ao fato de que é preciso entender de forma mais concreta o local da memória, outras críticas surgem no sentido de lembrar que Halbwachs estava preso às ideias de Durkheim e devido a isso teria introduzido o coletivo devido a essa influência.

Com isso, Viana (2006) defende o argumento de que a realidade passada é uma coisa, a consciência presente da realidade passada é outra. O autor separa essas duas variáveis no sentido de afirmar que não é o passado que reconstrói o presente, mas sim a consciência do passado que é responsável por isso. Assim, o autor afirma que a mente humana está ancorada no presente, sendo a memória ou a consciência virtual que se mantem ativa ou inativa.

Outra crítica ao pensamento de Halbwachs vem de Bloch, historiador e colega de Halbwach na Universidade de Strasbourg. Bloch escreve em 1925 que era a favor de uma integração entre as ciências humanas, lamentando que a memória jurídica e os costumes foram deixados de lado por seu colega sociólogo (BLOCH, 1925, p.76). 
Weber e Pereira (2010) afirmam que o conceito de memória social é questionável para Bloch, porque, em muitos casos, podemos estar usando erroneamente o termo, em questões que envolvem apenas a comunicação entre os indivíduos. Importante destacar que as críticas de Bloch foram importantes para os estudos posteriores em torno do conceito de memória social.

Outro ponto bastante questionado por Bloch é a transmissão de memória. Para o autor a relação entre o presente e o passado é uma linha tênue, não sendo possível, portanto, estabelecer uma distinção, já que o "atual e o inatual está longe de se ajustar necessariamente pela média matemática de um intervalo de tempo" (BLOCH, 2001, p.61).

Neste sentido Bloch acredita que as palavras "memória social" são expressivas e podem ser utilizadas, entretanto, sem confundir os mecanismos pelos quais um indivíduo ou uma sociedade guardam suas lembranças (WEBER e PEREIRA 2010). Os autores explicitam que o grupo mantém viva a sua memória a partir do momento em que os mais idosos não negligenciem a transmissão das representações aos mais jovens daquele grupo.

Outro argumento de Bloch é que a memória, tanto a coletiva como a individual, não conserva exatamente o passado, ela o reconstrói incessantemente, partindo do presente. Toda a memória é um esforço $(\mathrm{BLOCH}, 1925$, p.77). A memória precisa ser repensada ao longo do tempo, tal fato só é repensado por Halbwachs pelo menos vinte anos depois.

Outro crítico das ideias de Halbwachs é o psicólogo e médico francês Charles Blondel. $\mathrm{O}$ autor lecionava em Strasbourg e, também, era contemporâneo de Halbwachs. Juntamente com Marc Bloch e Lucien Febvre, eles formaram um dos grupos acadêmicos franceses mais importantes dos anos 1920 (MUCCHIELLI, 1999).

Cordeiro (2015) afirma que:

Blondel foi um dos fundadores da Psicologia Coletiva (ou a psicossociologia), campo fundado para explicar como o espírito humano e suas operações estão ligados as influências que os grupos exercem sobre os seus membros. Segundo a autora, a Psicologia Coletiva de Blondel coloca-se como pressuposto que o biológico é condição do social (Halbwachs, 1929) para se focar mais especificamente nas influências exercidas pelo coletivo no indivíduo (CORDEIRO,2015, p. 52). 
Blondel faz duras críticas ao trabalho de Halbwachs, alegando que o sociólogo invade a sua área de atuação, a psicologia, criticando o que denominou de "imperialismo sociológico" ou "pansociologismo" (MUCCHIELLI, 1999, p. 116). No tocante à memória, a crítica mais contundente de Blondel reforça a ideia de que nem todas as lembranças precisam de quadros sociais ${ }^{4}$ para se apoiar.

Blondel então critica a forma pela qual a memória individual era reduzida ao fenômeno coletivo (SANTOS, 2003, 38). Este é o ponto principal da teoria de Halbwachs, onde o autor afirma que mesmo sozinho não deixamos de pertencer aos quadros sociais que nos influenciam, apesar das ausências ou invisibilidade do ser.

Outro autor que debate a ideia de memória coletiva é o sociólogo austríaco Michael Pollak. Discípulo de Pierre Bourdieu, tem em seu campo de estudo o problema da identidade social em situações limites. O autor possui uma abordagem mais construtivista trazendo uma análise sobre o processo de construção da memória coletiva, aparecendo os conceitos de memória subterrânea, as disputas entre memórias e o enquadramento da memória.

Para Pollak a memória é um elemento constituinte do sentimento de identidade, tanto individual como coletiva, na medida em que ela é também um fator extremamente importante do sentimento de continuidade e de coerência de uma pessoa ou de um grupo em sua reconstrução de si (POLLAK, 1992).

Sobre o conceito de memórias subterrâneas o autor as classifica como sendo aquelas que fazem oposição a "Memória oficial" que determinados grupos sociais querem esquecer. $\mathrm{O}$ autor é contrário às ideias de Halbwachs, e acentua o "caráter destruidor, uniformizador e opressor da memória coletiva nacional" (POLLAK, 1989, p. $4)$.

Sua análise parte do ponto de vista dos excluídos e dos marginalizados, ressaltando a importância que a história oral proporciona para a memória subterrânea como parte integrante das culturas minoritárias dominadas pela memória nacional. Nesse ponto, Pollak chama a atenção para o que ele delimitou como sendo uma disputa entre memórias.

\footnotetext{
${ }^{4} \mathrm{Na}$ ideia de Halbwachs, os quadros sociais da memória são pontos de referências para a construção subjetiva de lembranças. Eles determinam o que deve ser lembrado, esquecido, silenciado ou comemorado pelos indivíduos.
} 
Pollak (1989) revela que uma vez rompido o tabu, uma vez que as memórias subterrâneas conseguem invadir o espaço público, reivindicações múltiplas e dificilmente previsíveis se acoplam a essa disputa da memória, no caso, as reivindicações das diferentes nacionalidades.

Nessa disputa o autor chama a atenção para o poder que a memória oficial exerce sobre a subterrânea, muitas das vezes, esse poder não remete forçosamente à oposição entre Estado dominador e sociedade civil, podendo ser encontrado com mais frequência nas relações entre grupos minoritários e sociedade englobante (POLLAK, 1989, p. 5).

Surge então o enquadramento da memória como sendo o limite que a memória de grupo possui, não podendo ser construída aleatoriamente, devendo satisfazer a certas exigências daquele grupo para se justificar.

\begin{abstract}
O trabalho de enquadramento da memória se alimenta do material fornecido pela história. Esse material pode sem dúvida ser interpretado e combinado a um sem-número de referências associadas; guiado pela preocupação não apenas de manter as fronteiras sociais, mas também de modificá-las, esse trabalho reinterpreta incessantemente o passado em função dos combates do presente e do futuro (POLLAK, 1989, p. 6).
\end{abstract}

Pollak (1989) demonstra que a memória é enquadrada na tentativa de salvaguardar, de maneira mais ou menos consciente, o sentimento de pertencimento e fronteiras sociais de determinados grupos de tamanhos diferentes. O passado é lembrado no sentido de manter uma certa coesão daqueles que se filiam a determinados grupos e instituições, definindo assim o seu lugar.

Percebe-se, então, que a discussão quanto ao conceito de memória possui diversos aspectos e críticas com vários pontos de vistas. No sentido de avançar na discussão, a presente pesquisa observa o papel da memória na formação dos espaços urbanos. São nesses locais onde os indivíduos interagem uns com os outros, reforçando com isso as ideias trazidas até o momento.

A respeito da formação de determinado espaço urbano Pensavento (2005, p. 14) explica que uma cidade inventa seu passado e cria o seu futuro para explicar o seu presente. A autora afirma que para pensar cidade no presente é preciso olhar para o passado e com isso planejar projetos de renovação do espaço urbano para o futuro. 


\begin{abstract}
O tempo das cidades é múltiplo e está sempre a ser construído, pois a cidade é uma contínua reinvenção do mundo no espaço: desde o tempo do presente, onde se realizam as opções políticas e se decidem as intervenções sobre o urbano, a cidade se reconstrói continuamente, tendo por horizonte o passado e o futuro (PENSAVENTO, 2005, p.14).
\end{abstract}

As feiras livres na cidade de Boa Vista, no Estado de Roraima parecem ser um bom exemplo do que Pensavento relata. Esses locais trazem a lembrança do passado recente, ainda quando havia a prática do garimpo no interior do estado, quando os garimpeiros, antes de partir, se dirigiam até as feiras livres no sentido de se abastecerem de produtos para consumirem no garimpo.

Para pensar nesse contexto é preciso entender que as feiras livres são carregadas de significação humana, "onde o relacionamento entre as pessoas ultrapassa suas diferenças de cultura, raça, credo, de tal maneira que as contradições passam despercebidas” (ROMANO, 2004, p. 1). Dessa forma, as feiras livres de Boa Vista/RR, são lugares carregados de simbolismos.

Esse parece ser o atrativo para fazer desses locais um tradicional ponto de compras da população roraimense. É esse simbolismo que faz a Feira do Garimpeiro ter a força que tem aos domingos, a Feira do Produtor, que funciona todos os dias, leva alimento de qualidade para os seus frequentadores, a Feira do São Francisco, como sendo a mais antiga e ainda permanece como sendo um tradicional ponto de encontro da classe média boavistense.

Outro local bastante simbólico para a população de Boa Vista é o Centro Comercial Caxambú. Localizado no Centro de Boa Vista lá estão reunidos os vendedores ambulantes organizados como microempreendedores individuais. $\mathrm{O}$ espaço foi cedido pela Prefeitura de Boa Vista utilizando a mesma lógica de ocupação de camelódromos de outras cidades como o Rio de Janeiro e São Paulo.

\title{
A FORMAÇÃO DAS FEIRAS LIVRES EM BOA VISTA/RR
}

Feiras e mercados, como fenômeno histórico e socioeconômico, já eram, desde a Idade Média na Europa, um meio de se movimentar a economia local de um dado território (DAVIDE, 2010), sendo que no Brasil colônia já se encontravam feiras onde a 
população podia se abastecer de mercadorias (DA SILVA, 1997). A seguir haverá a descrição das feiras mais significativas da cidade de Boa Vista/RR, descrevendo brevemente sua história e importância local.

\section{FEIRA DO SÃO FRANCISCO}

Considerada a feira mais antiga da cidade de Boa Vista/RR, a Feira do São Francisco está localizada dentro do Mercado Municipal São Francisco, no bairro de mesmo nome. O local passou por uma ampla reforma feita pela Prefeitura Municipal de Boa Vista, sendo entregue à população no ano de 2018. O local hoje conta com um espaço moderno, com diversos boxes que oferecem vários serviços.

O local é um tradicional ponto de encontro das famílias de classe média (principalmente) que se reúnem aos sábados e domingos pela manhã. A história oficial da feira começa em 1979, quando o Governador do Território Federal de Roraima à época, Otomar de Souza Pinto, consolida a feira, mas sua criação é datada do ano de 1967, realizada pelo então Prefeito da Cidade de Boa Vista, Antônio Maciel da Silveira (SANTOS, 2019).

Sua criação tinha o propósito de atender os garimpeiros que vinham até a cidade para se abastecerem, sendo que a sobra dos produtos era vendida para o restante da população local, o que ocasionava uma grande elevação dos preços das mercadorias. É o que revela Santos (2019) ao mencionar que:

\footnotetext{
As mercadorias que chegavam para abastecer a população vinham de diversos estados brasileiros, em longas viagens de barco, as quais acarretavam deterioração dos alimentos. Devido a este fator, os comerciantes preferiam vender para os garimpeiros, que compravam em grande quantidade. Apenas o que restava era vendido para a população da cidade, o que gerava grande inflação (SANTOS, 2019, np).
}

Apesar de sofrerem com algumas intervenções nas melhorias estruturais e a inserção de novos comerciantes, pode-se afirmar que no local está presente a memória social de uma época remota, os antigos comerciantes permanecem com as lembranças dos tempos do garimpo e do início da feira, guardando assim as características originárias do local. A figura 01 demonstra a Feira do São Francisco após a reforma. 
Santos (2019) confirma que o prédio do Mercado Municipal é um centro que guarda fazeres específicos, conhecimentos dos produtores rurais e memórias da época do garimpo, quando tudo era vendido no mesmo lugar e não havia muita especialização do comércio.

Figura 01: Feira do São Francisco em Boa Vista/RR

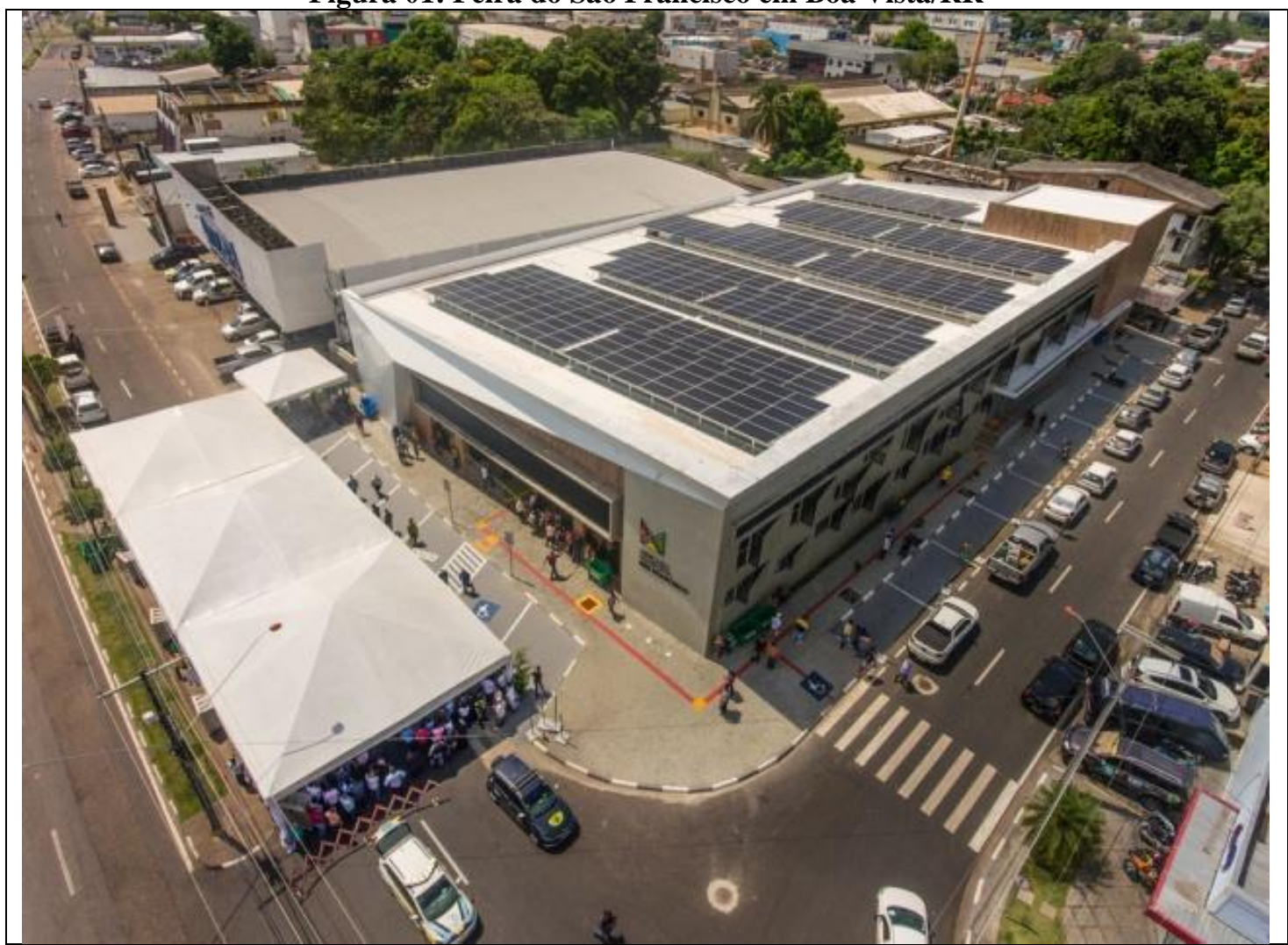

Fonte: Prefeitura de Boa Vista (2018).

Desse modo, a Feira do São Francisco permanece como sendo um pequeno pedaço da história do comércio roraimense. O local surgiu no sentido de explorar as atividades comerciais de um determinado nicho de mercado, o comércio de produtos para os garimpeiros de Roraima, mas a feira existe até os dias atuais como sendo um ponto tradicional das famílias boa-vistenses, guardando com isso traços da memória social do local. 


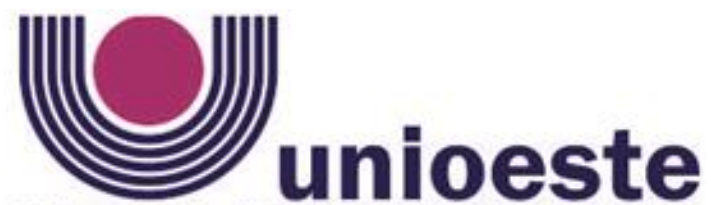

Universidade Estadual do Oeste do Paraná

e-ISSN 1981-0253

A Feira do Garimpeiro está localizada entre os bairros Asa Branca, Tancredo Neves e Caimbé na cidade de Boa Vista/RR. Farias e Freitas (2014) afirmam que essa feira funciona há mais de vinte anos e o comércio inicial do bairro esteve concentrado em um pequeno núcleo, sendo que o elemento promotor do surgimento da Feira do Garimpeiro foi a abertura de um supermercado. A figura 02 demonstra a extensão da Feira do Garimpeiro.

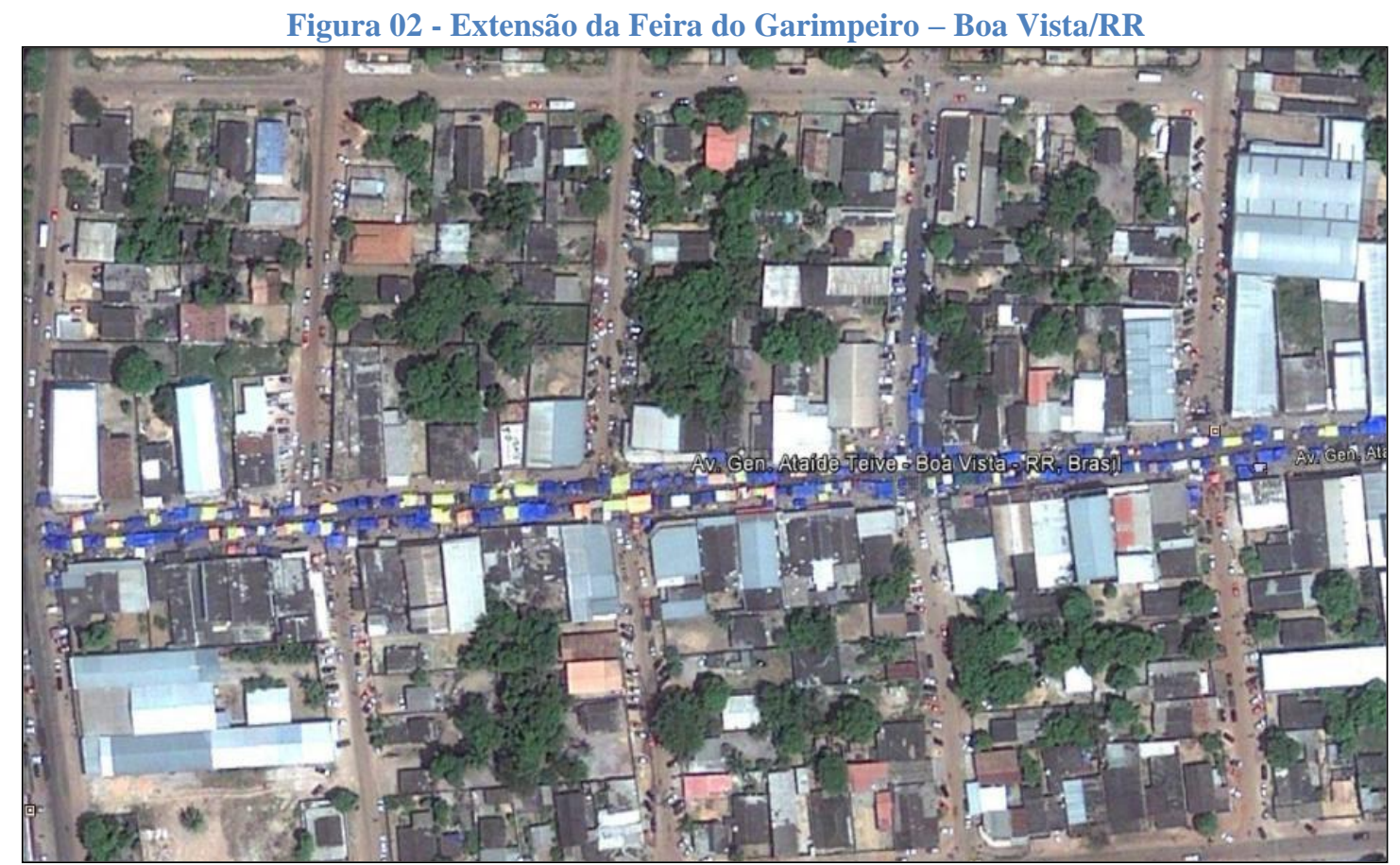

Fonte: Elaboração própria. Mapa extraído com base em Google Earth (2015).

Este local era responsável por abastecer de alimentos as pessoas que moravam no bairro Asa Branca e bairros vizinhos, bem como abastecer os garimpeiros, daí então surge o nome de Feira do Garimpeiro. No local reúnem-se todos os domingos aproximadamente 650 vendedores e mais de 30 mil pessoas circulando (FARIAS, VERAS e PAIXÃO, 2013, p. 125).

Nascimento, Farias e Freitas (2014) trazem uma visão mais caleidoscópica da própria Feira do Garimpeiro, questionando que a feira foi evoluindo quanto aos tipos de produtos que são comercializados nela. Nesta metamorfose, da Feira do Garimpeiro, a dinâmica comercial se faz presente, apresentando as atividades comerciais provenientes da produção agrícola. 
No local é encontrado o comércio de bens de consumo duráveis e tecnológicos, assim como a venda de aparelhos de telefonia móvel, produtos manufaturados e industrializados, em destaque na figura 03, os produtos de importação, fabricados em sua maioria nos países de fronteira, República Bolivariana da Venezuela e República Cooperativista da Guiana.

Figura 13 - Produtos comercializados na Feira do Garimpeiro

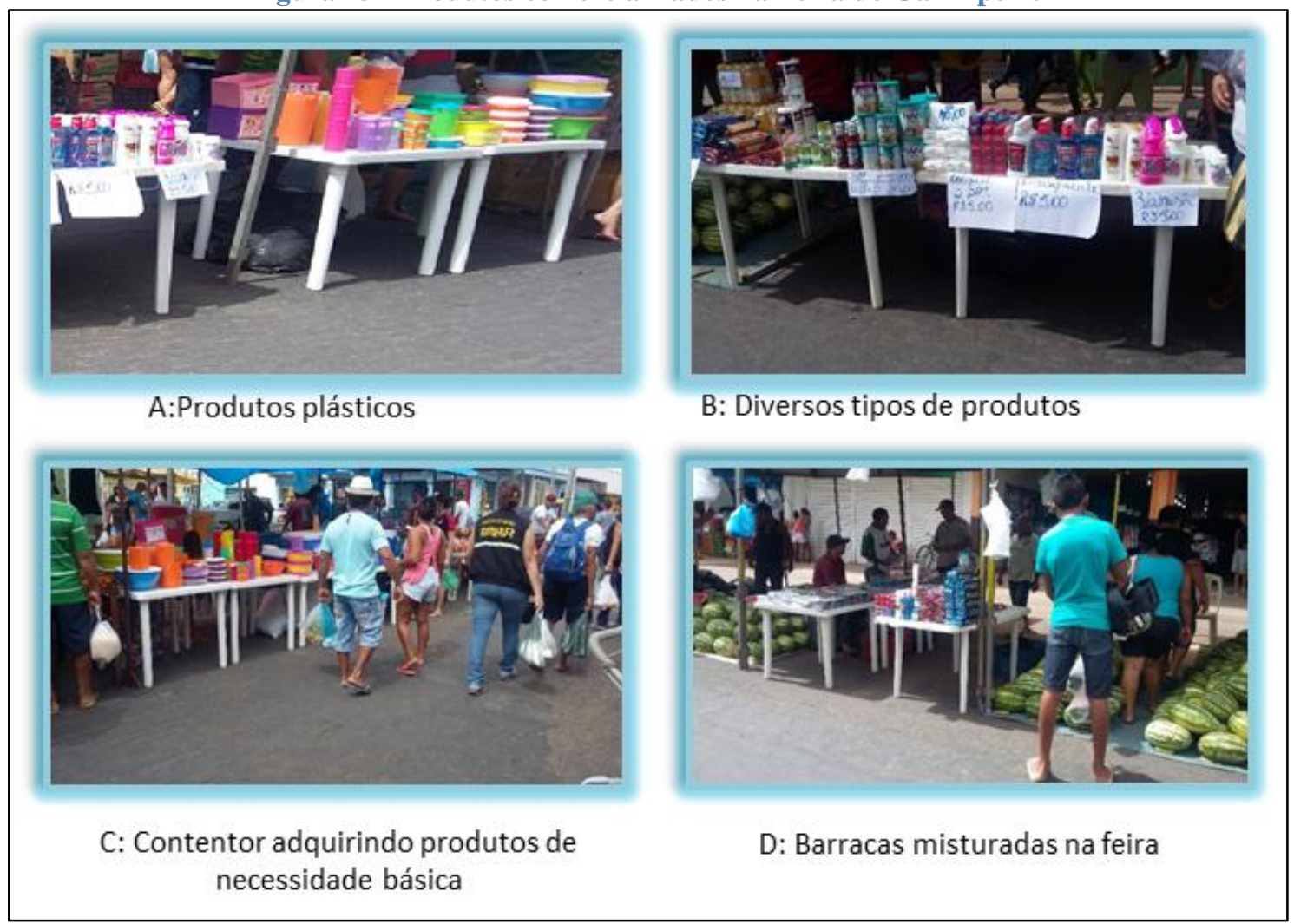

Fonte: FERREIRA \& SENHORAS (2015)

Dessa forma, percebe-se que a dinâmica implementada atualmente pela população boa-vistense na Feira do Garimpeiro é a mesma desde a sua inauguração, mantendo assim a memória social daquele local preservada, uma vez que a memória de um grupo de pessoas foi tipicamente passada a várias gerações.

\section{FEIRA DO PRODUTOR}

A Feira do Produtor Rural, localizada no bairro São Vicente, em Boa Vista/RR, foi inaugurada no ano de 1993, pelo então Governador da época Otomar de Souza 
Revista eletrônica de Ciências Sociais e Filosofia Alamedas unioeste

Pinto. A figura 04, demonstra a Feira do Produtor Rural, o local possui mais de duzentas e cinquenta bancas, sendo cerca de cinquenta e cinco delas destinadas à comercialização de frutas, legumes e verduras. Sua missão era proporcionar a comercialização de produtos regionais frescos, direto do produtor rural para $\mathrm{o}$ consumidor.

Figura 042 - Feira do Produtor Rural

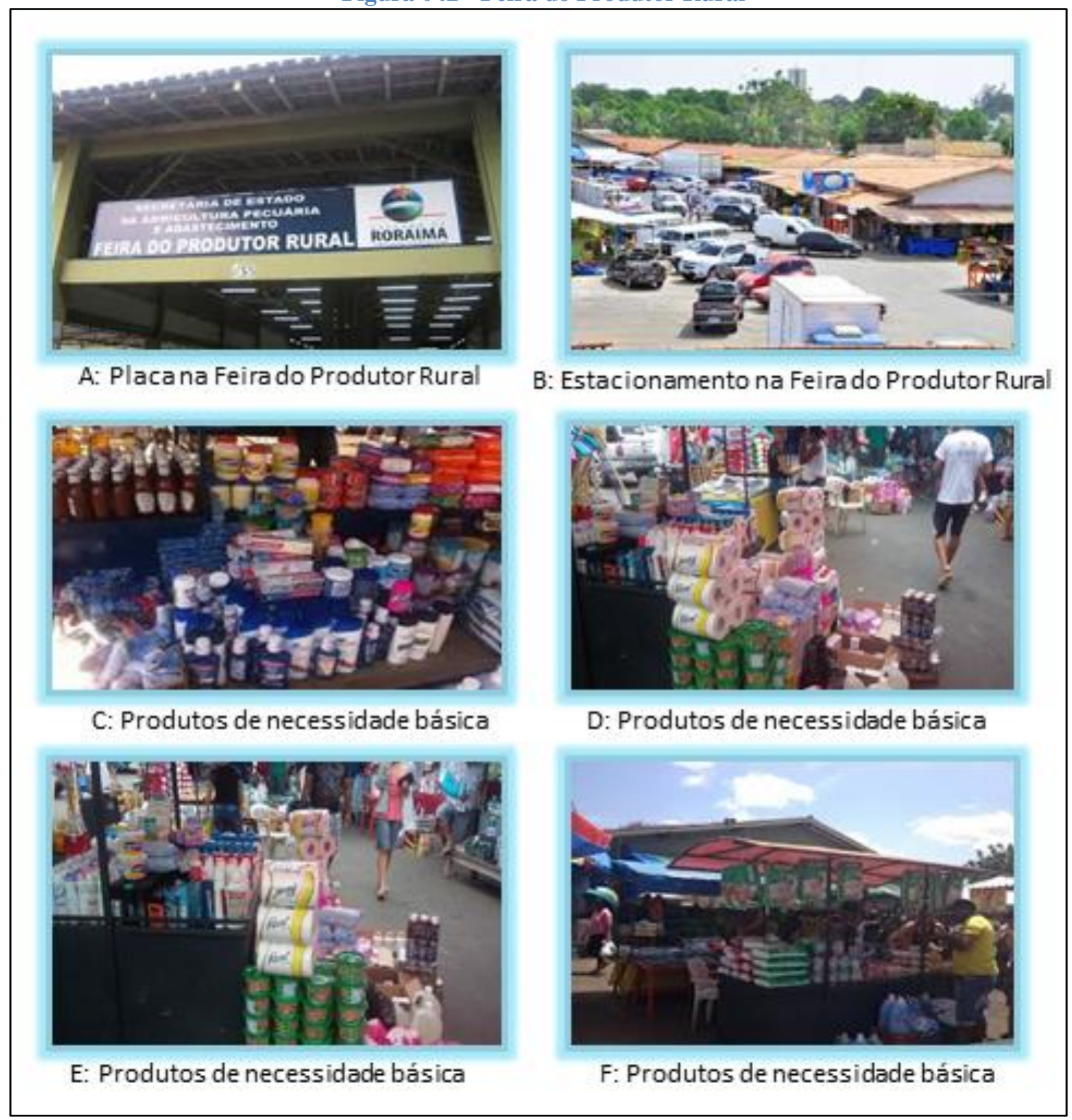

Fonte: FERREIRA \& SENHORAS, (2015)

A Feira do Produtor Rural é o que pode se compreender como sendo uma mistura de feira livre, um mercado público e centro de distribuição. Pode ser 
considerado como o maior centro de comércio popular de Roraima, possui uma variada exposição de mercadoria diversificadas, com bancas, quiosques com restaurantes, sendo comercializadas frutas, legumes, animais abatidos e vivos.

A feira é cercada por muros e portões que são abertos diariamente, sendo concentrado no final de semana o maior fluxo de frequentadores. Segundo Folha Web (2018),

\begin{abstract}
a Feira do Produtor também é um polo de comercialização de produtos vindos de outros Estados. No local há estabelecimento que vende frutos do mar, vindos do Nordeste e do Estado do Pará. Também é vendida a farinha produzida no Acre e no Amapá. A farinha produzida no interior do Estado geralmente é comercializada na própria localidade ou segue para exportação.
\end{abstract}

Quanto ao objeto de estudo desta pesquisa, o que pode ser notado é que a memória social daqueles produtores rurais na Feira do Produtor de Boa Vista/RR foi afetada devido a invasão de atravessadores que dominaram o local. Esse fato modificou a dinâmica da feira causando diversos prejuízos, dentre eles, tirar do produtor rural a oportunidade de vender as mercadorias produzidas em sua propriedade.

\title{
FORMAÇÃO DO CENTRO COMERCIAL CAXAMBÚ
}

O Centro Comercial Caxambú (com acento mesmo) está localizado no Centro de Boa Vista e possui uma grande quantidade de vendedores ambulantes que vendem uma grande variedade de produtos, sendo uma referência para a população boa-vistense. Quanto aos aspectos de memória social, o nome do local faz uma homenagem ao primeiro vendedor ambulante da cidade.

Ferreira (2015, p. 138) relata que sua criação é datada de 13 de dezembro de 2002 em homenagem ao amazonense Manuel Barbosa de Araújo Filho, conhecido como Caxambú, o primeiro ambulante da cidade. No ano de 2009 o Centro Comercial Caxambú recebeu uma grande reforma na parte estrutural, ganhando cobertura, melhoria nas instalações elétricas, drenagem e ventilação.

Com uma arquitetura moderna e um espaço amplo, o centro comercial possui 142 quiosques, configurando-se como um dos principais pontos de comércio informal 
de Boa Vista. Antes do Centro Comercial Caxambú, os comerciantes distribuíam seus produtos nas calçadas das Av. Sebastião Diniz e Jaime Brasil.

Ferreira (2015, p. 138) revela que os comerciantes que ali estão implantados pagam, obrigatoriamente, aluguel e todos possuem alvará de funcionamento, sendo que a grande maioria deles são cadastrados como Microempreendedores Individuais. A figura 05 contempla a Feira do Caxambú. O local é dividido em duas alas, sendo oferecidos à população equipamentos eletrônicos, roupas, bolsas, cosméticos, brinquedos e acessórios em geral. 
Revista eletrônica de Ciências Sociais e Filosofia Alamedas unioeste

Figura 05 - O Centro Comercial Caxambú

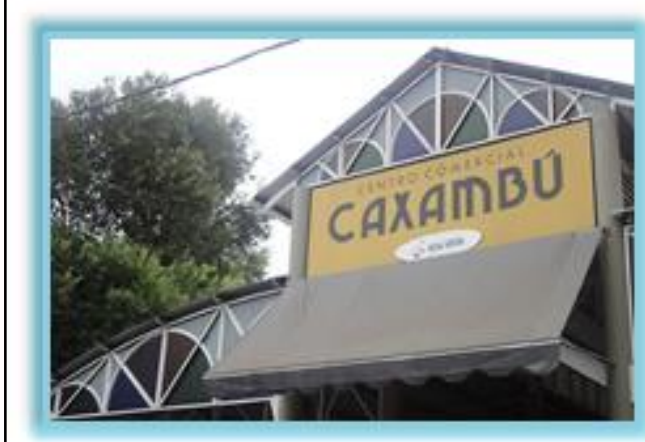

A: Placa de entrada

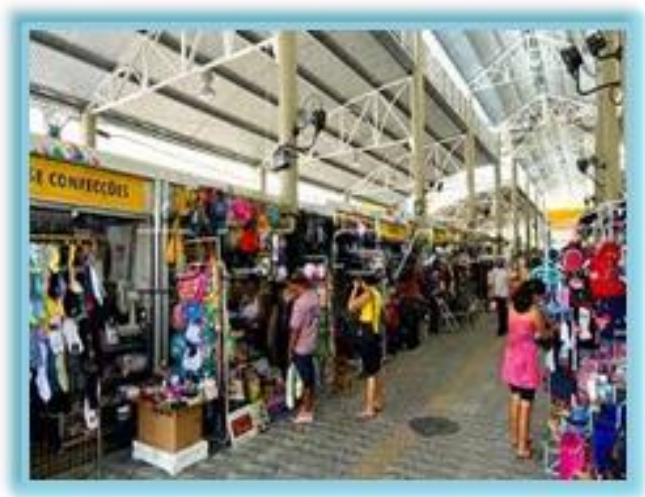

C: Lojas comercializando diversos produtos

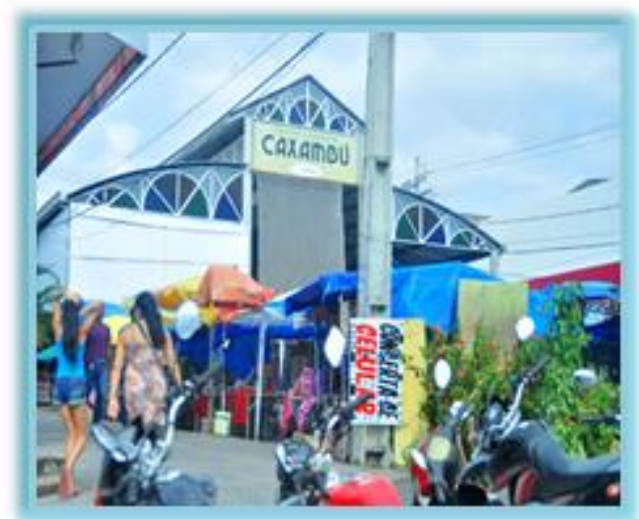

E: Frente do Centro Comercial com barracas

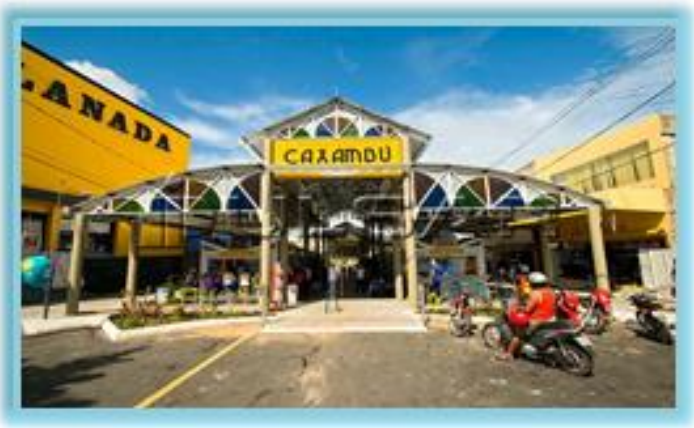

B: Frente do Centro Comercial

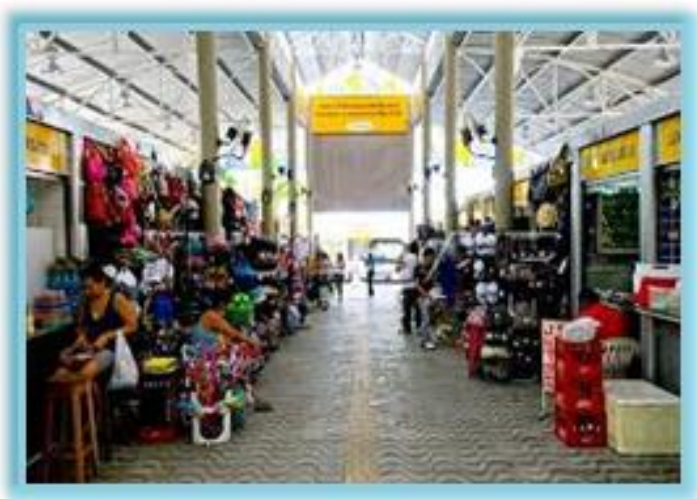

D: Lojas comercializandodiversos produtos

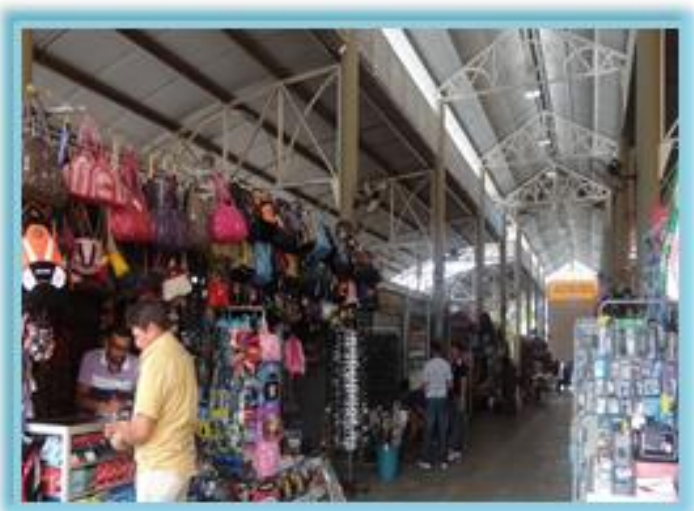

F: Lojas comercializandodiversos produtos

Fonte: Folha de Boa Vista. Adaptado pelo autor.

No local é possível encontrar, também, serviços de reparos em relógios, como comerciantes que vendem acessórios e oferecem serviços de reparos para celular. A venda de CDs e DVDs piratas é outro tipo de produto bastante procurado pela população de maneira geral. O comércio formiga fronteiriço é praticado no local de 
forma intensa pelos próprios difusores, como a venda de produtos eletrônicos (FERREIRA, 2015, p. 139).

No local também é possível encontrar uma certa quantidade de indígenas que vendem seus produtos nas calçadas das lojas, em frente ao centro comercial, ou de forma itinerante, circulando no entorno. Os produtos vendidos por eles são artesanatos, acessórios como: brincos, pulseiras, cordões e peças de madeira, todas de fabricação própria.

A decisão da Prefeitura de Boa Vista em instalar os vendedores ambulantes no Centro Comercial Caxambú, na região do centro da cidade, ativa a memória social de outros locais espalhados pelo Brasil, por exemplo o Rio de Janeiro, que criou o Camelódromo no Centro da cidade (no governo de Leonel Brizola) e o centro de tradições nordestinas (conhecida como feira dos paraíbas, no governo de César Maia), ou ainda, na cidade de São Paulo onde existe a Região do Brás e da 25 de março como referência a esses tipos de comércio.

Com isso pode-se afirmar que o Centro Comercial Caxambú, localizado no Centro de Boa Vista, preserva um importante traço de memória social para aquela parte da população, uma vez que, na busca por produtos populares a própria população ativa a sua memória social na busca por esses tipos de produtos.

\section{CONSIDERAÇÕES FINAIS}

O artigo em questão tratou sobre as memórias sociais nas feiras livres na cidade de Boa Vista/RR. A relevância do tema se faz presente nas discussões em áreas como a história, a psicologia, as ciências sociais, entre outras. Sendo debatido aqui por diversos autores como Maurice Halbwachs e Michael Pollak.

Os locais escolhidos para o estudo foram as principais feiras livres e um centro comercial popular na cidade de Boa Vista/RR, esses locais guardam objetos de memória social bastante característicos de uma sociedade localizada no Norte do Brasil. Sendo essa formada por migrantes de diversos locais, e atualmente, conta com a presença maciça de venezuelanos que alteram o ambiente da pesquisa.

Ao longo do texto o leitor percebe que o conceito de memória foi ampliado ao longo dos anos, sendo impulsionado por Halbwachs na década de 20 e 30 ascendendo 
ainda mais o debate sobre o tema. O autor é seguidor de Durkheim e então fixa conceitos sobre memória individual e memória coletiva, acreditando que a primeira é resultado da convivência com outros indivíduos ou grupos sociais.

Halbwachs recebe críticas de diversos autores, um deles é Charles Blondel, que critica a forma pela qual a memória individual era reduzida ao fenômeno coletivo. Para Blondel, o termo memória coletiva poderia ser usando de forma equivocada, por exemplo, em questões que envolvem apenas a comunicação entre os indivíduos não se caracterizando dessa forma uma memória coletiva.

Outro autor que debate com Halbwachs é Michael Pollak. Discípulo de Pierre Bourdieu, o autor chamou a atenção para o que ele considerou como sendo processos de dominação e submissão das diferentes versões e memórias. Para ele os conceitos de memória subterrânea, disputas entre memórias e o enquadramento da memória não podem ficar ausentes nessa discussão.

Outro ponto discutido nesta pesquisa foi o papel da memória na formação dos espaços urbanos. São nesses locais onde os indivíduos interagem entre si e reforçam os conceitos trazidos até o momento. Para poder pensar nas cidades hoje é necessário resgatar as suas memórias, dessa forma planejar projetos de renovação do espaço urbano para o futuro.

Com isso o objeto de estudo da pesquisa demonstra ser um exemplo disso. Em pelo menos duas feiras livres da cidade de Boa Vista/RR guardam-se a lembrança desse passado recente. A prática do garimpo fez com que as feiras do São Francisco e do Garimpeiro fossem criadas para atender a uma demanda que existia na época.

Com isso, o problema da pesquisa, que era conhecer como se deu a construção da memória social nas feiras livres na cidade de Boa Vista/RR, foi respondido através da metodologia proposta e os conceitos gerados pelos autores durante a própria pesquisa.

$\mathrm{Na}$ análise do problema pôde-se perceber que existem traços de memória social na formação de duas feiras livres. A Feira do Garimpeiro mantém aos domingos a mesma dinâmica de seu início, são centenas de barracas vendendo grande diversidade de produtos. Já a Feira do São Francisco mantém a sua memória social ativa por guardar na lembrança dos seus frequentadores e feirantes resquícios de sua formação. 
Outro local bastante carregado de simbolismo é o Centro Comercial Caxambú. No local percebe-se a memória social presente entre os comerciantes, sendo guardadas as lembranças de quando atuavam na informalidade, espalhados pelas ruas de Boa Vista. Outra característica de memória social presente está na lembrança dos camelódromos de outros centros comerciais, como o Camelódromo no Rio de Janeiro e na Rua 25 de Março e no Brás em São Paulo.

Por outro lado, a Feira do Produtor vai na contramão do que foi estudado até aqui. O local foi criado para atender a demanda dos produtores rurais, para escoarem sua produção diretamente para a população, eliminando assim o uso de atravessadores, garantindo produtos mais frescos com preços mais competitivos.

O que pode ser percebido é que essa não foi a dinâmica observada no local, a Feira do Produtor, logo após a sua inauguração, foi tomada por atravessadores que montavam suas barracas e vendiam as mercadorias que compravam diretamente dos produtores rurais, perdendo com isso o caráter para o qual foi criada. Conclui-se, então, que o artigo em tela cumpriu com o objetivo estabelecido.

Como sugestão para futuras pesquisas é preciso estudar como será mantida a memória social presente nas feiras livres e do Centro Comercial Caxambú em Boa Vista/RR, sabendo que nesses locais existem famílias que garantem o seu sustento e ajudam na manutenção da memória desses lugares muitas vezes esquecidos por parte da população.

\section{REFERÊNCIAS BIBLIGRÁFICAS}

BOA VISTA, Lei $n^{\circ}$ 402, de 12 de novembro de 1996. Diário Oficial do Município de Boa Vista. Boa Vista. RR. Câmara Municipal de Boa Vista. 1996.

BLOCH, M. Mémoire collective, tradition et coutume a propôs d'un livre récent. In: Revue de Synthése Historique. Tome XL, Paris, 1925. Disponível em: <http://gallica.bnf.fr>. Acesso em: 22/08/2020.

Apologia da História. Ou o ofício de historiador. Rio de Janeiro: Jorge Zahar Editor, 2001.

CORDEIRO, V. D. Por Uma Sociologia da Memória: Análise e Interpretação da Teoria da Memória social de Maurice Halbwachs. 2015. p. 167 Dissertação (Mestrado) Faculdade de Filosofia, Letras e Ciências Humanas da Universidade de São Paulo, São Paulo. 
DA SILVA, F. C. T. Pecuária e formação do mercado interno no Brasil-colônia. Estudos Sociedade e Agricultura, 2013. Disponível em: < https://revistaesa.com>. Acesso em: 11 de jan. de 2021.

DAVIDE, D. MANUFATURAS E CORPORAÇÕES in ECO, Umberto. Idade Média - Bárbaros, cristãos e muçulmanos. Córdova: Publicações Dom Quixote, 2010.

EHRLICH, S. Aprendizagem e Memória Humanas. Rio de Janeiro, Zahar, 1979, p. 233.

FARIAS, M. V. A; VERAS, A. S. S; PAIXÃO, S. U. A. Caracterização socioeconômica e espacial do subcentro comercial da avenida Ataíde Teive em Boa Vista - RR. Revista Textos e Debates. Boa Vista, n. 19, p. 121-141. Jan/jun. 2013.

FILLOUX, J. C. A Memória. 1966, 1-134. Ed. Saber Atual.

FERREIRA. M. A. A. Comércio Formiga Fronteiriço entre Venezuela e Brasil (2010 - 2014). 2015. p. 187 (Dissertação). Programa de Pós-Graduação em Sociedade e Fronteiras. Universidade Federal de Roraima. Boa Vista.

FOLHA WEB. Feira é o maior polo de venda da agricultura familiar em Roraima. Folha de Boa Vista, Roraima, 07 mai. 2018. Disponível em: <https://folhabv.com.br>. Acesso em: 02 de set. de 2020.

HALBWACHS, M. A memória social. Tradução de Beatriz Sidou. $2^{\mathrm{a}}$ ed. São Paulo: Centauro, 2006.

IBGE - Instituto Brasileiro de Geografia e Estatística. Censo Demográfico 2010. Resultados Preliminares do Universo do Censo Demográfico 2010. Rio de Janeiro: IBGE, 2010.

LICEA, F. V. Microcentros Urbanos. Desarrollo Urbano. Inmobiliare, 2012. Disponível em: <http://inmobiliare.com>. Acessado em: 30 de nov. de 2020.

MUCCHIELLI, L. Pour une psychologie collective: l'héritage durkheimien d'Halbwachs et sa rivalité avec Blondel durant l'entre-deux-guerres. In: Revue d'histoire des sciences humaines. n. 1. 1999. Paris. Disponível em: <http://www.cairn.info > Acesso em: 22 de out. de 2019.

NASCIMENTO, C. H. C; FARIAS, M. C; FREITAS, P. R. C. Traços culturais da paisagem de Boa Vista/RR: o bairro Asa Branca e a contribuição da migração nordestina da década de 1980. $3^{\circ}$ Colóquio Ibero Americano Paisagem Cultural, patrimônio e projeto - desafios e perspectivas. Belo Horizonte. Set. 2014. 
PEnSAVEnTO, S. J. Cidade, Espaço e Tempo: Reflexões Sobre a Memória e o Patrimônio Urbano - Cadernos do LEPAARQ - Textos de Antropologia, Arqueologia e Patrimônio - V. II, n4. Pelotas, RS: Editora da UFPEL. Ago/Dez 2005.

POLLAK, M. Memória e identidade social. In: Estudos Históricos, 5. Rio de Janeiro, 1992.

1989.

Memória, esquecimento, silêncio. In: Estudos Históricos, 2. Rio de Janeiro,

ROMANO, L. Edifícios e Mercados Gaúchos: Uma arquitetura dos Sentidos. Dissertação de Mestrado, Universidade Federal do Rio Grande do Sul. Porto Alegre. 2004.

SANTOS, M. S. Memória social e teoria social. Coimbra: Annablume, 2012.

SANTOS, T. M. F dos. Um pouco da História do Mercado São Francisco. Meu Artigo. Brasil Escola. 2019?. Disponível em: <https://meuartigo.brasilescola.uol.com.br>. Acesso em: 06 de set. de 2019.

SILVA, G.F. HALBWACHS, M. A memória social. Tradução de Beatriz Sidou. $2^{\mathrm{a}}$ ed. São Paulo: Centauro, 2013. Aedos, Porto Alegre, v. 8, n. 18, ago. 2016.

VALE, A.F. Migração e territorialização: as dimensões territoriais dos nordestinos em Boa Vista, RR. 2007. Tese (Doutorado em Geografia). Faculdade de Ciências e Tecnologia, Universidade Estadual Júlio de Mesquita Filho”, Presidente Prudente.

VIANA, N. Memória e sociedade: uma breve discussão teórica sobre memória social. Espaço Plural - Ano VI - No 14 - $1^{\circ}$ Semestre de 2006. Disponível em: <www.unioeste.br/saber>. Acesso em: 12 de ago. de 2019.

WEBER, R. e PEREIRA, E. M. Halbwachs e a Memória: Contribuições à História Cultural. Revista Territórios e Fronteiras V.3 N.1 - Jan/Jun 2010 Programa de PósGraduação em História do ICHS/UFMT. 